\title{
Mycoplasma molare, a New Canine Mycoplasma Species
}

\author{
S. ROSENDAL \\ FAO/WHO International Reference Center for Animal Mycoplasmas, Institute of Medical Microbiology, \\ University of Aarhus, DK 8000 Aarhus C., Denmark
}

\begin{abstract}
Five glucose-fermenting Mycoplasma strains were isolated from the pharynx of dogs. Biological and serological studies demonstrated that this group of mycoplasmas was different from the established canine species and from other glucose-fermenting Mycoplasma species of animal or human origin. The isolates appear to constitute a new species, for which the name Mycoplasma molare is proposed ( $\mathrm{L}$. adj. molaris, millstone-like; intended to refer to the heavy film reaction produced by the strains which resembles the pattern on the surface of a millstone). The type strain of $M$. molare is H 542 (=ATCC 27746; =NCTC
\end{abstract} 10144).

Three Mycoplasma strains which could not be identified with any of the known canine Mycoplasma species ( $M$. spumans, $M$. canis, $M$. maculosum, $M$. edwardii, and $M$. cynos) are characterized and described in another communication (S. Rosendal, Acta Pathol. Microbiol. Scand. Sect. B, in press). The strains were found to constitute a separate serological group, temporarily designated serogroup A. Later, two additional strains were isolated which shared biochemical and serological properties with the members of serogroup A. The present investigation was carried out to determine whether these five strains constitute a new species.

\section{MATERIALS AND METHODS}

Mycoplasma strains. Strains H 542, H 512, and H 551 were isolated from the pharynx of three healthy dogs. Strains H 1011 and $H 1021$ were isolated from the pharynx of two other dogs showing mild respiratory distress. All isolates were cloned three times. The type strains of the canine Mycoplasma species and of the glucose-fermenting, non-canine Mycoplasma species were used in the comparative serological examinations and are listed in Table 1. Two other canine strains, MH4962 and MH5408, received from Armstrong et al. (1), were also compared with these presumably new strains. Strain H 542 was chosen as the reference strain for serogroup A.

Medium. All organisms were cultured in medium (B) described previously (6).

Morphological studies. Four-day-old colonies were examined at a magnification of $\times 40$ by use of a stereomicroscope. Fluid cultures were studied at a magnification of $\times 1,000$ with a dark-field microscope.

For electron microscopy, strain $\mathrm{H} 542$ was cultivated in a liquid medium containing $2 \%$ pleuro- pneumonialike organism serum fraction (Difco) instead of $20 \%$ horse serum. The culture was incubated at $37 \mathrm{C}$ for $48 \mathrm{~h}$. The cells were sedimented by centrifugation $(27,000 \times g)$ and washed in $2.5 \%$ heart infusion broth (Difco). The procedure used for fixation, sectioning, and staining was that described by Black et al. (2).

Filtration studies. A culture of strain H 542 incubated for $48 \mathrm{~h}$ was diluted $1: 10$ in phosphatebuffered saline at $\mathrm{pH} 7.4$ with $0.2 \%$ gelatin added. The ability of the mycoplasmas to pass filters was examined by using Swinnex-25 adapters and membrane filters (Acropor). The number of colonyforming units (CFU) per milliliter was determined on the original suspension and after filtration through filters of the following pore sizes: $450,200,100$, and $50 \mathrm{~nm}$.

Reversion experiments. The fourth in vitro passage of strain H 542 was grown on plates containing no bacterial inhibitors. After 4 days of incubation at 37 $\mathrm{C}$, the plates were examined for bacterial colonies. This examination was repeated after each of five consecutive passages on noninhibiting substrate.

Growth at 22, 27, and $37 \mathrm{C}$. A culture of strain $\mathrm{H}$ 542 was diluted 10 -fold and streaked on solid medium. Three plates were inoculated from each dilution. The plates were incubated at 22,27 , and 37 $\mathrm{C}$, respectively, and examined for growth every second day for 10 days.

Test for cholesterol requirement. The test for cholesterol requirement was carried out in principle as described by Edward (3). A twice-washed suspension of strain $\mathrm{H} 542$ was diluted 10 -fold, and $0.01 \mathrm{ml}$ of each dilution was streaked on each of the following substrates: (i) serum-free agar plates (CA); (ii) same as $\mathrm{CA}$, but with $10 \mu \mathrm{g}$ of palmitic acid per $\mathrm{ml}$ and $0.5 \%$ bovine serum albumin added (CB); (iii) same as CB, but with $5 \mu \mathrm{g}$ of cholesterol solution added per $\mathrm{ml}$ (CC). Bovine serum albumin was dissolved in water, and palmitic acid and cholesterol were dissolved in ethanol.

The inoculated plates were observed for growth 
TABLE 1. Strains of canine and glucose-fermenting non-canine Mycoplasma species used for serological comparison

\begin{tabular}{|c|c|}
\hline Species & Strain \\
\hline \multicolumn{2}{|c|}{ Mycoplasma spumans ...........PG13 } \\
\hline \multicolumn{2}{|c|}{ 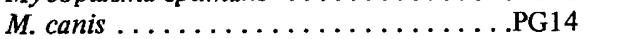 } \\
\hline \multicolumn{2}{|c|}{ M. maculosum . . . . . . . . . . . PG15 } \\
\hline \multicolumn{2}{|c|}{ M. edwardii $\ldots \ldots \ldots \ldots \ldots \ldots \ldots \ldots$} \\
\hline \multicolumn{2}{|c|}{ M. cynos .............. 831} \\
\hline \multicolumn{2}{|c|}{$M$. felis $\ldots \ldots \ldots \ldots \ldots \ldots \ldots \ldots$} \\
\hline \multicolumn{2}{|c|}{ M. mycoides subsp. mycoides . . . . . . PG1 } \\
\hline \multicolumn{2}{|c|}{ M. mycoides subsp. capri . . . . . . . . . PG3 } \\
\hline \multicolumn{2}{|c|}{ 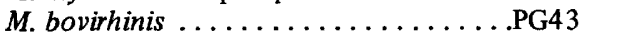 } \\
\hline \multicolumn{2}{|c|}{$M$. gallisepticum $\ldots \ldots \ldots \ldots \ldots \ldots$. PG 31} \\
\hline \multicolumn{2}{|c|}{$M$. anatis $\ldots \ldots \ldots \ldots \ldots \ldots \ldots \ldots \ldots$} \\
\hline \multicolumn{2}{|c|}{ M. neurolyticum $\ldots \ldots \ldots \ldots$................ A } \\
\hline \multicolumn{2}{|c|}{ M. pulmonis $\ldots \ldots \ldots \ldots \ldots$. . . . Ash } \\
\hline M. hyorhinis $\ldots \ldots \ldots$ & $\ldots \ldots \ldots \ldots$. . . 29 \\
\hline M. caviae ......... & $\ldots \ldots \ldots$ G122 \\
\hline M. pneumoniae ....... & $\ldots \ldots \ldots . M a c$ \\
\hline M. fermentans ........ & $\ldots \ldots \ldots \ldots$ PG18 \\
\hline M. sp. Armstrong et al. (1) & $\ldots \ldots \ldots$. MH4942 \\
\hline M. sp. Armstrong et al. (1) & . . . . . MH5408 \\
\hline
\end{tabular}

every second day during incubation at $37 \mathrm{C}$ for a period of 10 days.

Dependence for cholesterol was also examined by indirect methods, as the isolates were tested for sensitivity to digitonin and sodium-polyanetholsulfonate (SPS) ( E. A. Freundt, B. E. Andrews, H. Ern $\phi$, M. Kunze, and F. T. Black, manuscript submitted for publication), respectively. Disks of filter paper soaked with $0.02 \mathrm{ml}$ of a $1.5 \%(\mathrm{wt} / \mathrm{vol})$ solution of digitonin (E. Merck A. G., Darmstadt, W. Germany) were placed on agar plates inoculated with approximately $10^{5} \mathrm{CFU} / \mathrm{ml}$. Correspondingly, the test for SPS sensitivity was performed with filter paper disks soaked with $0.02 \mathrm{ml}$ of a $5 \%(\mathrm{wt} / \mathrm{vol})$ solution of SPS (K\&K Laboratories, Inc., Calif.).

Biochemical studies. The five isolates were examined for fermentation of glucose and mannose, hydrolysis of arginine and urea, phosphatase activity, formation of film and spots, reduction of $0.045 \%$ 2,3,5-triphenyltetrazolium chloride, and hemolytic activity against guinea pig erythrocytes. The details concerning the biochemical tests are given elsewhere (S. Rosendal, Acta Pathol. Microbiol. Scand. Sect. B, in press).

Serological studies. Antiserum against strain H 542 was produced as described previously (8). Antisera against the strains listed in Table 1 were available from the FAO/WHO Reference Center for Animal Mycoplasmas, Aarhus, Denmark.

Indirect immunofluorescence was carried out with unfixed colonies and the agar-block technique (8). Growth inhibition was performed with serum-impregnated disks and by use of agar plates without yeast extract and with reduced horse serum $(2.5 \%)$ content. The indirect hemagglutination test was carried out with formalinized sheep erythrocytes (5). The metabolic inhibition test was performed as glucose-fermentation inhibition by the procedure described by Taylor-Robinson et al. (9).
Electrophoresis examination. The electrophoretic pattern of strain H 542 was compared with the patterns of the type strains of the canine Mycoplasma species by a method described previously (7).

\section{RESULTS}

Morphological characteristics. Four-day-old colonies of the isolates showed the typical "fried-egg" appearance with a marked central spot (Fig. 1). After prolonged incubation on horse serum agar or after 4 days of cultivation on the "egg-yolk" medium (4), a very heavy film and spots reaction was produced (Fig. 2). As a rule, growth in fluid cultures reached a maximum level after 2 days of aerobic incubation at 37 C. Dark-field microscopy of the isolates in the logarithmic growth phase showed pleomorphic, nonmotile organisms. Many conglomerates and coccoid elements, and also ring forms, were seen. Electron microscopy of strain H 542 showed pleomorphic cells as well. The cells were surrounded by the typical triplelayered membrane (Fig. 3).

Filterability. Before dilution and filtration, the culture of strain $\mathrm{H} 542$ contained $10^{8}$ $\mathrm{CFU} / \mathrm{ml}$. After 10 -fold dilution and filtration through 450-, 200-, 100-, and 50-nm filters, the filtrates contained $5 \times 10^{5}, 4 \times 10^{2}, 0$, and 0 $\mathrm{CFU} / \mathrm{ml}$, respectively.

Reversion. No bacterial-like colonies developed during five consecutive passages of strain $\mathrm{H} 542$ on noninhibiting substrate.

Growth at 22, 27, and $37 \mathrm{C}$. No growth was observed at $22 \mathrm{C}$. On the plates incubated at 27 C, growth was demonstrable after 4 days. At this temperature the colonies reached a size of $0.3 \mathrm{~mm}$ in 10 days. At $37 \mathrm{C}$, growth was visible as early as 2 days, and after 10 days the largest colonies measured $1.5 \mathrm{~mm}$ in diameter.

Cholesterol requirement. The suspension of strain H 542 used to inoculate the media for determining cholesterol requirement contained $10^{8} \mathrm{CFU} / \mathrm{ml}$. No growth was found on CA plates, whereas growth appeared on $\mathrm{CB}$ plates inoculated with undiluted suspension, and with $10^{-1}$ and $10^{-2}$ dilutions. On CC plates, growth was vigorous, and furthermore, growth appeared on plates inoculated with a $10^{-3}$ dilution. To investigate whether growth on the CB plates was caused by transfer of traces of medium, one colony was picked up with a Pasteur pipette. The colony was crushed in a tube containing $1.0 \mathrm{ml}$ of phosphate-buffered

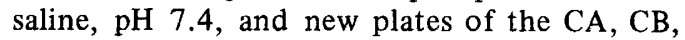
and $\mathrm{CC}$ substrates were inoculated with this colony suspension. After 4 days of incubation, growth was found on the CC plates. After 6 days, growth was also found on the CB plates. 


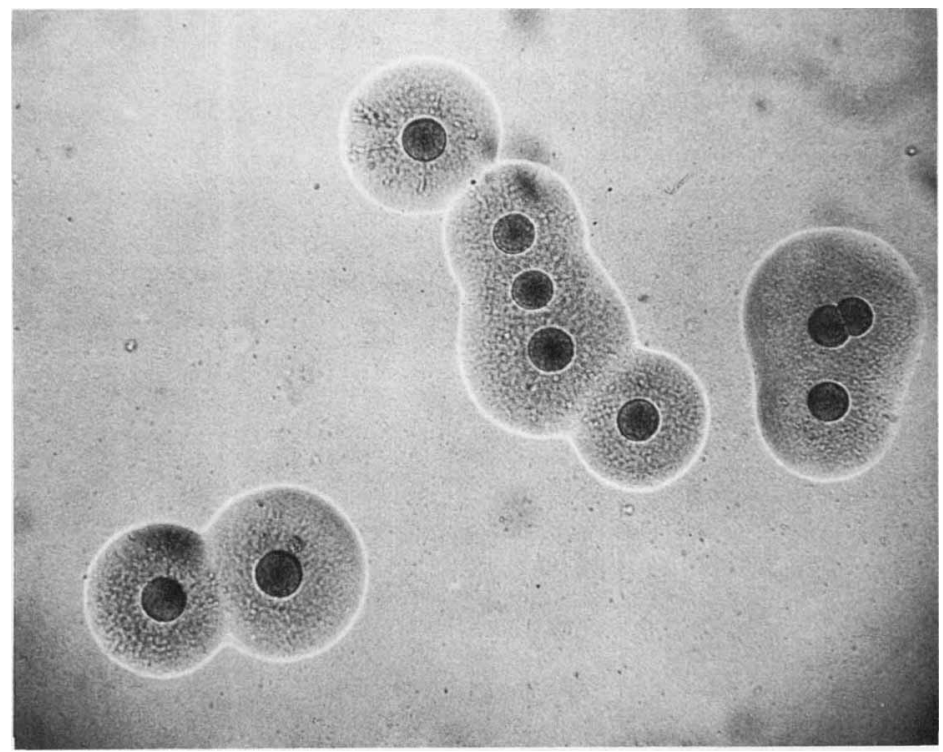

FIG. 1. Mycoplasma molare H 542. Unstained colonies of "fried-egg" morphology (X40).

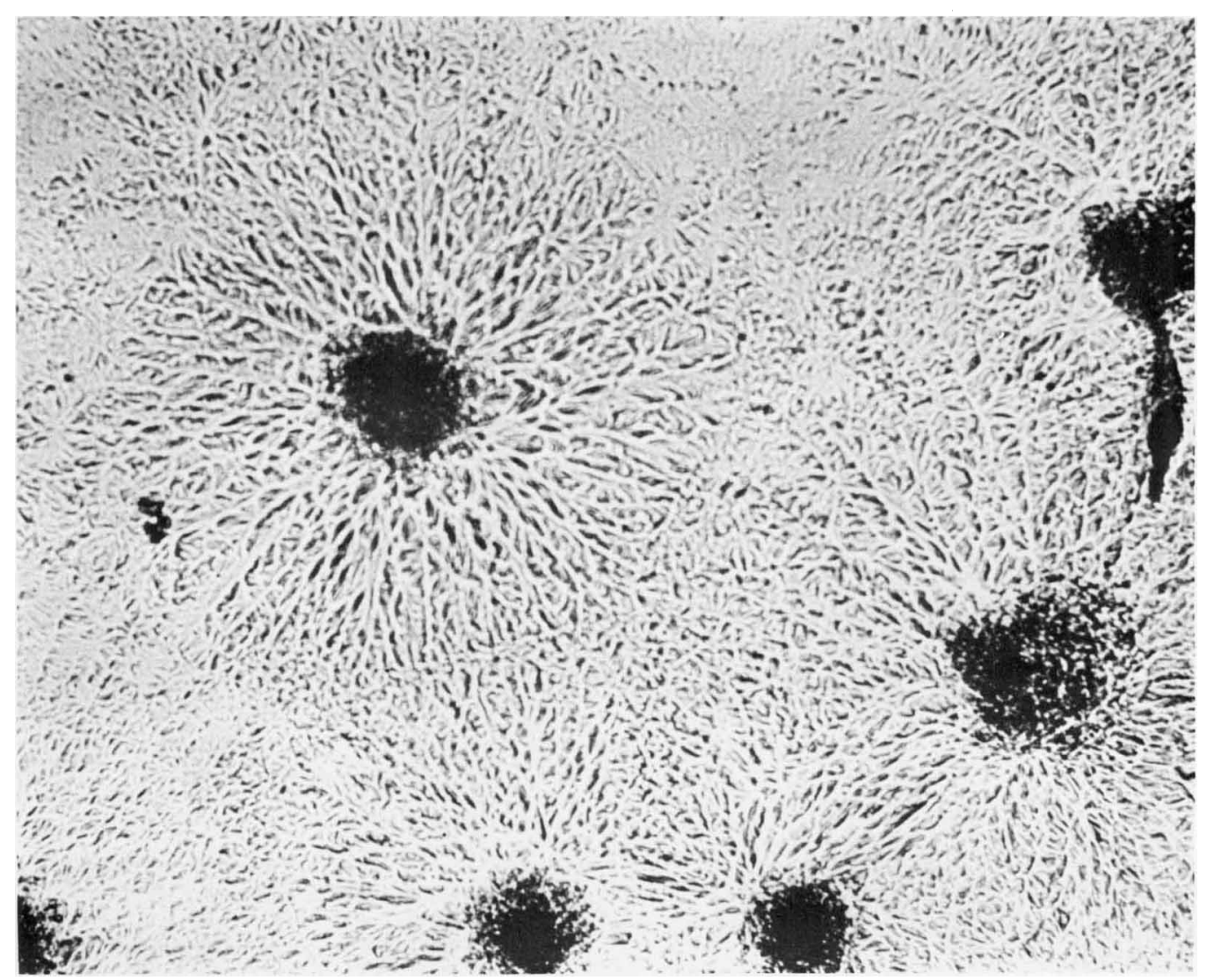

FIG. 2. Mycoplasma molare H 542. Four-day-old colonies grown on egg-yolk medium showing heavy film and spots formation (X40). 


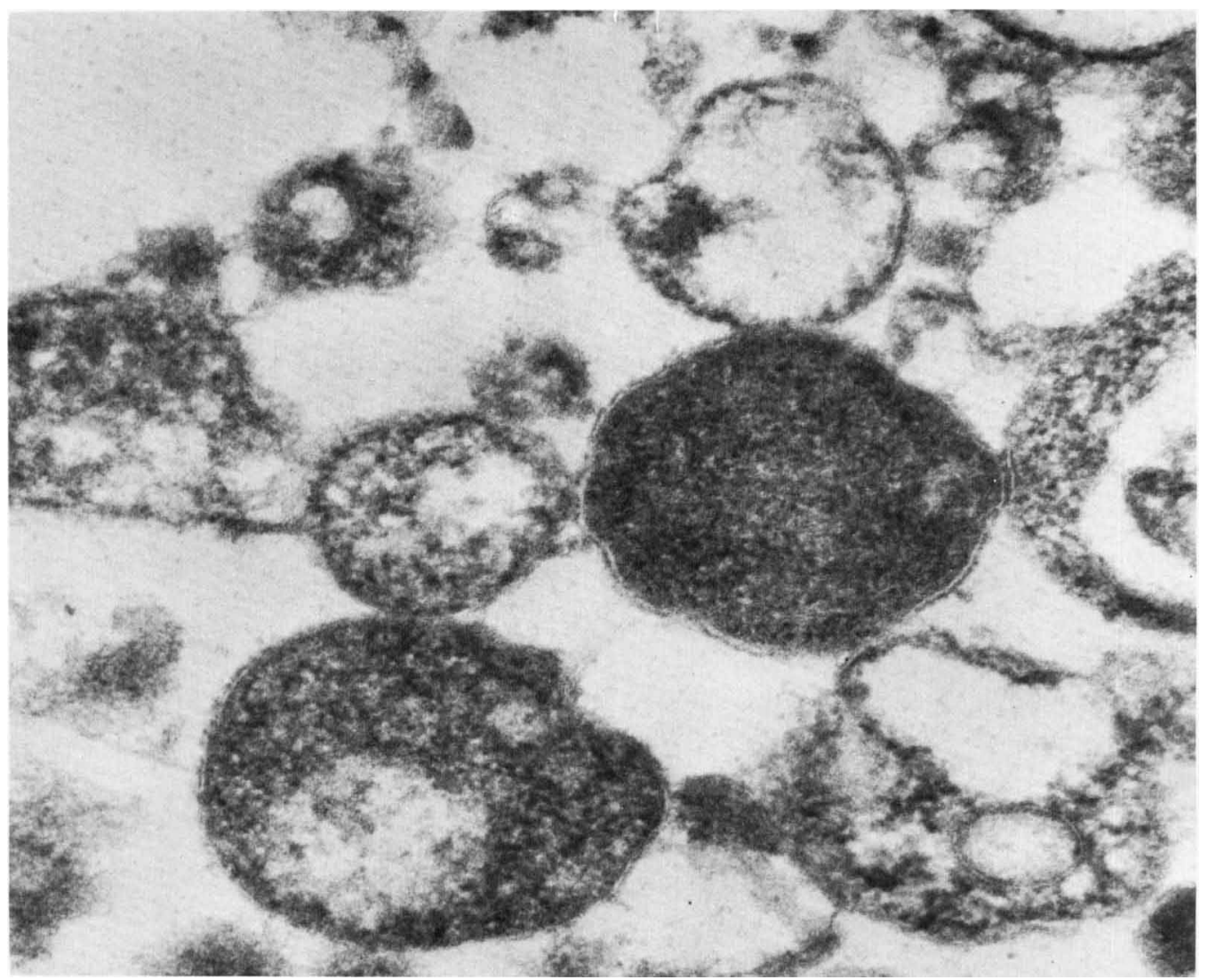

FIG. 3. Mycoplasma molare $H$ 542. Thin-section electron micrograph of fluid culture pellet $(\times 100,000)$.

No growth was observed on the CA plates during 10 days. After this procedure, colonies from the $\mathrm{CB}$ plates were passed eight times. When the bovine serum albumin was removed from the CB plates, no growth appeared during 10 days of incubation. The isolates were found to be sensitive to both digitonin and SPS (Table 2).

Biochemical characteristics. The strains were found to be unable to catabolize urea and arginine. Positive reactions appeared in the glucose and mannose tests, and film and spots were formed after only a few days of incubation. At a magnification of $\times 40$, the film reaction encircling the colonies resembled the pattern on the surface of a millstone. Furthermore, the isolates reduced tetrazolium and hemolyzed guinea pig erythrocytes. The phosphatase test was negative. The positive reaction for glucose fermentation and the negative arginine and phosphatase reactions are properties shared by $M$. canis and $M$. edwardii (Table 2).

Serology. Using indirect immunofluorescence, the dilution of 1:80 was found to be the highest dilution of strain $\mathrm{H} 542$ antiserum which gave strong fluorescence in homologous titration. Colonies of the isolates all gave strong fluorescence with this antiserum in the dilutions of $1: 10$ and $1: 80$. Strain MH4942 and MH5408 as well as the type strains of the canine and the glucose-fermenting noncanine Mycoplasma species (Table 1) did not give any fluorescence with strain $\mathrm{H} 542$ antiserum.

In the growth inhibition test, all isolates were inhibited by antiserum against strain $\mathrm{H} 542$. No cross-reactions were found in a double-cross test between strain $\mathrm{H} 542$ on one side and the canine type strains and glucose-fermenting, non-canine type strains on the other side (Table $3)$.

The metabolic inhibition test gave no crossreactions between strain $\mathrm{H} 542$ and the other canine or the glucose-fermenting strains (Table 3).

Indirect hemagglutination cross-titrations were performed with an antigen prepared from strain H 542. With this serological test also, no cross-reactions were found (Table 3 ).

Electrophoretic pattern. The electrophoretic 
pattern of strain H 542 seemed to be different from the patterns of $M$. spumans PG13, $M$. canis PG14, M. maculosum PG15, M. edwardii PG24, and $M$. cynos $\mathrm{H} 831$.

\section{DISCUSSION}

The morphology of the colonies, the presence of pleomorphic cells in fluid cultures, and the observation of a triple-layered membrane by electron microscopy indicate that the group of microorganisms described above belongs to the order Mycoplasmatales. This is further confirmed by the fact that some of the cells of these organisms are able to pass filters with pore sizes of $450 \mathrm{~nm}$ and $200 \mathrm{~nm}$ and that no reversion to bacterial-like forms develops during cultivation on substrate without bacteriostatics.

The sensitivity to digitonin and SPS indicates

TABLE 2. Biochemical reactions of the canine Mycoplasma species and the new species Mycoplasma molare ${ }^{a}$

\begin{tabular}{l|c|c|c|c|c|c}
\hline \multicolumn{1}{c|}{ Biochemical reaction } & M. spumans & M. canis & M. maculosum & M. edwardii & M. cynos & M. molare \\
\hline Glucose fermentation & $\div$ & + & $\div$ & + & + & + \\
Mannose fermentation & $\div$ & $(+)$ & $\div$ & $(+)$ & + & + \\
Arginine hydrolysis & + & $\div$ & + & $\div$ & $\div$ & $\div$ \\
Phosphatase production & + & $\div$ & + & $\div$ & + & $\div$ \\
Film and spots formation & $(\div)$ & $(\div)$ & + & $(\div)$ & + & + \\
Tetrazolium reduction & $(\div)$ & $(\div)$ & $(+)$ & $(+)$ & $(\div)$ & + \\
$\quad$ (aerobic) & $(+)$ & $(+)$ & $(+)$ & + & + & + \\
Tetrazolium reduction & & & & & + & + \\
(anaerobic) & + & + & $(+)$ & + & + & + \\
Hemolysis & + & + & + & + & + & + \\
Sensitivity to digitonin & + & + & + & + & + & + \\
Sensitivity to sodium- & + & & & & + \\
polyanethol-sulfonate & & & & & & + \\
\hline
\end{tabular}

a Symbols: + , positive; $\div$, negative; $(+)$, nearly all strains positive; $(\div)$, nearly all strains negative.

Table 3. Results of serological tests using strain $\mathrm{H} 542$ antigen and antisera against the type strains of canine and of glucose-fermenting Mycoplasma species of human or other animal source

\begin{tabular}{|c|c|c|c|}
\hline \multirow[b]{2}{*}{ Antisera against } & \multicolumn{3}{|c|}{ Titers of serological tests } \\
\hline & $\begin{array}{l}\text { Growth } \\
\text { inhibi- } \\
\text { tion (mm) }\end{array}$ & $\begin{array}{c}\text { Metabolic } \\
\text { inhibi- } \\
\text { tion }\end{array}$ & $\begin{array}{l}\text { Indirect } \\
\text { hemagglu- } \\
\text { tination }\end{array}$ \\
\hline M. sp. H $542 \ldots \ldots \ldots \ldots \ldots$ & 5,0 & 1024 & 1024 \\
\hline M. spumans PG13 $\ldots \ldots \ldots \ldots \ldots$ & 0 & $<2$ & $<2$ \\
\hline M. canis PG14 . . . . . . . . . & 0 & $<2$ & $<2$ \\
\hline M. maculosum PG15 . . . . . . . . & 0 & $<2$ & $<2$ \\
\hline M. edwardii PG24 . . . . . . . . & 0 & $<2$ & $<2$ \\
\hline M. cynos H $831 \ldots \ldots \ldots \ldots$ & 0 & $<2$ & $\mathrm{ND}^{a}$ \\
\hline M. felis $\mathrm{CO} \ldots \ldots \ldots \ldots \ldots$ & 0 & $<2$ & ND \\
\hline M. mycoides subsp. mycoides PG1 .... & 0 & $<2$ & $<2$ \\
\hline M. mycoides subsp. capri PG3 . . . . . . & 0 & $<2$ & $<2$ \\
\hline M. bovirhinis PG43 . . . . . . . . & 0 & $<2$ & $<2$ \\
\hline M. gallisepticum PG31 . . . . . . . . & 0 & $<2$ & $<2$ \\
\hline M. anatis $1340 \ldots \ldots \ldots \ldots$ & 0 & $<2$ & ND \\
\hline M. neurolyticum Sabin A . . . . . & 0 & $<2$ & $<2$ \\
\hline M. pulmonis Ash . . . . . . . . . & 0 & $<2$ & $<2$ \\
\hline 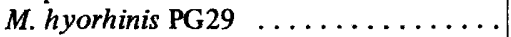 & 0 & $<2$ & ND \\
\hline M. caviae G122 ............. & 0 & $<2$ & ND \\
\hline M. pneumoniae Mac ........... & 0 & $<2$ & $<2$ \\
\hline M. fermentans PG18 . . . . . . . & 0 & $<2$ & ND \\
\hline 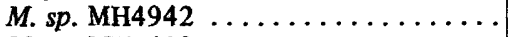 & 0 & ND & ND \\
\hline M. sp. MH5408 $\ldots \ldots \ldots \ldots \ldots \ldots$ & 0 & ND & ND \\
\hline
\end{tabular}

${ }^{a}$ ND, Not determined. 
that the organisms require cholesterol. The lack of growth on serum-free base media containing palmitic acid supports this assumption. The delayed and inferior growth on base medium plus bovine serum albumin is presumably due to traces of cholesterol contained in the albumin preparation. Finally, no growth appeared during incubation at $22 \mathrm{C}$. Therefore, it is concluded that the group of microorganisms belongs to the family Mycoplasmataceae.

Fermentation of glucose is a property which this group of mycoplasmas has in common with some canine species, namely $M$. canis, $M$. edwardii, and $M$. cynos.

By the indirect immunofluorescence and growth inhibition tests, the group was found to be antigenically homogeneous. However, serologically these Mycoplasma strains are different from those of the other canine species and from the glucose-fermenting animal and human Mycoplasma species. This has been demonstrated by means of four serological tests, namely indirect immunofluorescence, grow th inhibition, metabolic inhibition, and indirect hemagglutination. Strain H 542 was, furthermore, shown by indirect immunofluorescence and growth inhibition to be unrelated to strains MH 4942 and MH 5408 isolated by Armstrong et al. (1). Finally, it has been demonstrated that the electrophoretic pattern is different from those of the type strains of the canine species. These results lead to the conclusion that the group of microorganisms represents a new species, for which the name Mycoplasma molare is proposed. The Latin adjective molaris means millstone-like, referring to the heavy film reaction which resembles the pattern on the surface of a millstone. Strain H 542 is designated as the type strain of $M$. molare. This strain has been deposited in the American Type Culture Collection, Rockville, Md., and in the National Collection of Type Cultures, London, England, where it has been given the numbers ATCC 27746 and NCTC 10144 , respectively.

$M$. molare has been isolated only from the pharynx of dogs, in two cases from dogs with mild respiratory distress ( $\mathrm{H} 1011$ and $\mathrm{H} 1021)$. Whether $M$. molare is pathogenic for dogs remains to be determined.

\section{REPRINT REQUESTS}

Address reprint requests to: Dr. S. Rosendal, Institute of Medical Microbiology, University of Aarhus, DK-8000 Aarhus C., Denmark.

\section{LITERATURE CITED}

1. Armstrong, D., J. G. Tully, B. Yu, V. Morton, M. H. Friedman, and L. Steger. 1970. Previously uncharacterized mycoplasma isolates from an investigation of canine pneumonia. Infect. Immunity 1:1-7.

2. Black, F. T., A. Birch-Andersen, and E. A. Freundt. 1972. Morphology and ultrastructure of human T-mycoplasma. J. Bacteriol. 111:254-259.

3. Edward, D. G. 1971. Determination of sterol requirement for Mycoplasmatales. J. Gen. Microbiol. 69:205-210.

4. Fabricant, J., and E. A. Freundt. 1967. Importance of extension and standardization of laboratory tests for the identification and classification of mycoplasma. Ann. N.Y. Acad. Sci. 14:50-58.

5. Krogsgaard-Jensen, A. 1971. Indirect hemagglutination with Mycoplasma antigens: effects of $\mathrm{pH}$ on antigen sensitization of tanned fresh and formalinized sheep erythrocytes. Appl. Microbiol. 22:756-759.

6. Rosendal, S. 1973. Mycoplasma cynos, a new canine Mycoplasma species. Int. J. Syst. Bacteriol. 23:49-54.

7. Rosendal, S. 1973. Analysis of the electrophoretic pattern of mycoplasma proteins for the identification of canine Mycoplasma species. Acta Pathol. Microbiol. Scand. Sect. B 81:273-281.

8. Rosendal, S., and F. T. Black. 1972. Direct and indirect immunofluorescence of unfixed and fixed Mycoplasma colonies. Acta Pathol. Microbiol. Scand. Sect. B 80:615-622.

9. Taylor-Robinson, D., R. H. Purcell, D. C. Wong, and R. M. Chanock. 1966. A colour test for the measurement of antibody to certain Mycoplasma species based upon the inhibition of acid production. J. Hyg. 64:91-104. 